\title{
Effect of slaughtering conditions on lipid damage of chilled farmed turbot (Psetta maxima) muscle
}

\author{
By Hugo Lago, Javier Pena and Santiago P. Aubourg* \\ Food Technology Department, Instituto de Investigaciones Marinas (CSIC). Vigo (Spain) \\ ('Corresponding author: saubourg@iim.csic.es)
}

\section{RESUMEN}

Efecto de las condiciones de sacrificio sobre la alteración lipídica en músculo de rodaballo (Psetta maxima) de cultivo conservado en refrigeración.

El objetivo de este estudio fue evaluar el efecto que sobre la alteración lipídica (hidrólisis y oxidación) tiene el empleo de distintos tipos de hielo durante las etapas de sacrificio y refrigeración de rodaballo (Psetta maxima) cultivado. Se aplicó hielo líquido (SI) solo, o en combinación con ozono (OSI) y se comparó con hielo tradicional en escamas (FI). También se realizaron las medidas de valor $\mathrm{K}$ y contenido en trimetilamina (TMA). Se observó un pequeño efecto negativo del ozono sobre las oxidaciones primaria y secundaria, siendo considerados bajos los valores obtenidos y sin efecto sobre el contenido en ácidos poliinsaturados; asimismo, la presencia de ozono produjo un descenso en la formación de TMA. Al comparar el pescado de los tratamientos SI y FI, el primero reflejó menores pérdidas de calidad (valor K y TMA), al tiempo que no se pudo observar efecto diferencial sobre la oxidación e hidrólisis lipídicas.

PALABRAS CLAVE: Acuicultura - Alteración lipídica Hielo líquido - Ozono - Rodaballo - Sacrificio.

\section{SUMMARY}

Effect of slaughtering conditions on lipid damage of chilled farmed turbot (Psetta maxima) muscle.

The aim of the present study was to comparatively evaluate the effect of different kinds of icing systems employed for the slaughtering and post-mortem storage of cultured turbot (Psetta maxima) on lipid damage (hydrolysis and oxidation). Slurry ice (SI) alone or in presence of ozone (OSI) was applied and compared to the traditional flake ice ( $\mathrm{FI})$ treatment. K value and trimethylamine (TMA) formation were also assessed. Some negative effects of ozone presence could be observed on primary and secondary lipid oxidation development; however, oxidation values reached by individuals kept under OSI condition could not be considered high and did not lead to polyunsaturated fatty acid content losses; while ozone presence provided a slowing down of TMA formation. When compared to FI conditions, the employment of SI was found useful to inhibit quality losses (K value and TMA formation), while no differences in lipid hydrolysis or oxidation development could be observed.

KEY-WORDS: Farming - Lipid damage - Ozone Slaughtering - Slurry ice - Turbot.

\section{INTRODUCTION}

The assurance of both the quality and safety of fresh seafood is currently an important challenge. In order to inhibit the different mechanisms responsible for fish deterioration during chilled storage (Whittle et al., 1990; Olafsdóttir et al., 1997), recent research depends on advanced procedures. One such technology is slurry ice (SI) which, when employed in the place of traditional flake ice (FI), has shown many advantages such as a lower storage temperature, faster cooling, lower physical damage to the product and better heat exchange power (Yamada et al., 2002; Medina et al., 2009). Another profitable tool for damage inhibition is the employment of ozone and its decomposition products. Ozone is considered a powerful antimicrobial agent that is suitable for application in food in the gaseous and aqueous states leading to significant increases in the sensory quality and shelf-life of fish (Kim et al., 1999).

For several decades, fish technologists and the fish trade have been attracted by aquaculture development as a source of fish products. The slaughtering procedure can be regarded as a prominent topic in fish culture management. Whatever method is employed, a special consideration in terms of both the welfare of the fish and the quality of the final product, is required (Gregory, 2005). As a result, a large number of studies have been carried out during the last decade to check the effects of different slaughtering methods on the quality of cultured fish products. In such research, comparative studies on sensory and physical properties, as well as changes in protein, nucleotide and carbohydrate composition have been carried out (Morzel et al., 2003; Özogul and Özogul, 2004; Roth et al., 2007); however, research related to lipid fraction damage has been scarce, only accounting in some cases for a single lipid oxidation index (namely, thiobarbituric acid value) (Huidobro et al., 2001; Duran et al., 2008).

Among cultivated fish, turbot (Psetta maxima) is a flat fish species widely appreciated for its firm, white and flavorful flesh. Spain, and particularly its northwestern area, is the major European producer and exporter of farmed turbot (FAO, 2007). The aim of the present study was to comparatively evaluate the effect of different kinds of icing systems employed for the slaughtering and post-mortem storage of cultured 
turbot on lipid damage (hydrolysis and oxidation). For this, SI alone or in the presence of ozone (OSI treatment) was applied and compared to traditional FI. In this study, an assessment of endogenous enzymatic activity ( $\mathrm{K}$ value) and microbial activity (trimethylamine formation) was also carried out.

\section{MATERIALS AND METHODS}

\subsection{Icing systems}

Three different icing systems (FI, SI and OSI) were employed for farmed turbot slaughtering and post-mortem chilling storage.

FI was prepared with an Icematic F100 Compact device (Castelmac SPA, Castelfranco, Italy). The temperature of the $\mathrm{FI}$ was $-0.5^{\circ} \mathrm{C}$ with the temperature of the fish in the range of $0^{\circ} \mathrm{C}$ to $-0.5^{\circ} \mathrm{C}$.

SI was prepared using a FLO-ICE prototype (Kinarca S.A.U., Vigo, Spain). The composition of the SI binary mixture was $40 \%$ ice/ $60 \%$ water, prepared from filtered seawater (salinity: $3.3 \%$ ). The temperature of the $\mathrm{SI}$ mixture was $-1.5^{\circ} \mathrm{C}$ with the temperature of the fish in the range of $-1.0^{\circ} \mathrm{C}$ to $-1.5^{\circ} \mathrm{C}$.

The injection of ozone into the SI mixture was accomplished with a prototype provided by Cosemar Ozono (Madrid, Spain), with the redox potential adjusted to $700 \mathrm{mV}$ (0.20 mg ozone/L). In this batch, the ozone concentration was constantly monitored by checking the redox potential in the liquid phase. The temperatures of the OSI mixture and the corresponding fish were the same as in the case of the SI treatment.

\subsection{Fish material, slaughtering and chilled storage}

Fifty-four specimens of farmed turbot (Psetta maxima) (individual weight range: $1.45-1.65 \mathrm{~kg}$; individual length range: $37-42 \mathrm{~cm}$ ) were obtained (day 0) from an aquaculture facility (Isidro de la Cal, La Coruña, Spain) and slaughtered at the farm by immersion either in FI (18 individuals), SI (18 individuals) or OSI (18 individuals), respectively. Individuals were kept under such conditions for 24 hours until arrival at the laboratory. At this time (day 1), six individuals belonging to each icing condition were separated and divided into three groups (two individuals in each group) which were studied separately $(n=3)$; in all cases, the white muscle was separated, homogenized and taken for chemical analyses. The remaining fish were placed in an isothermal room at $2^{\circ} \mathrm{C}$ and were surrounded by either FI, SI or OSI, respectively, at a 1:1 fish to ice ratio. Fish sampling was then continued on days 3 and 6 of icing treatment, according to the same sampling design $(n=3)$. Throughout the experiment, the different kinds of ice were renewed when required.

\subsection{Proximate analyses}

Moisture content was determined by the difference between the weight of fresh homogenized muscle
(1-2 g) and the weight recorded after $4 \mathrm{~h}$ at $105^{\circ} \mathrm{C}$. Results were expressed as g water/ $100 \mathrm{~g}$ muscle.

Lipids were extracted by the Bligh and Dyer (1959) method, by employing a single-phase solubilization of the lipids using a chloroform-methanol (1:1) mixture. Quantification results were expressed as $\mathrm{g}$ lipid/ $100 \mathrm{~g}$ muscle.

$\mathrm{NaCl}$ content in fish muscle was determined by a modification of the Volhard method, which included boiling in $\mathrm{HNO}_{3}$, the neutralization of $\mathrm{NaCl}$ meq with excess of $\mathrm{AgNO}_{3}$, and final determination of the excess of $\mathrm{AgNO}_{3}$ meq by reverse titration with $\mathrm{NH}_{4} \mathrm{SCN}$ (AOAC, 1990). Results were calculated as $\mathrm{g} \mathrm{NaCl} / 100 \mathrm{~g}$ muscle.

\subsection{Lipid damage}

Free fatty acid (FFA) content was determined in the lipid extract of the fish muscle by the Lowry and Tinsley (1976) method based on complex formation with cupric acetate-pyridine followed by spectrophotometric $(715 \mathrm{~nm})$ assessment. Results were expressed as g FFA/ $100 \mathrm{~g}$ lipids.

The peroxide value (PV) was determined in the lipid extract of the muscle according to the ferric thiocyanate method (Chapman and McKay, 1949). Results were expressed as meq active oxygen/ kg lipids.

The thiobarbituric acid index (TBA-i) was determined in a $5 \%(\mathrm{w} / \mathrm{v})$ trichloracetic acid extract of the fish muscle (Vyncke, 1970). Results were expressed as mg malondialdehyde/ kg muscle.

Formation of fluorescent compounds was determined in the lipid extract of the muscle by measurements at $393 / 463 \mathrm{~nm}$ and $327 / 415 \mathrm{~nm}$ as previously described (Aubourg, 1999). The relative fluorescence (RF) was calculated as follows: RF $=F / F_{s t}$, where $F$ is the fluorescence measured at each excitation/emission maximum, and $F_{s t}$ is the fluorescence intensity of a quinine sulphate solution $\left(1 \mu \mathrm{g} / \mathrm{ml}\right.$ in $\left.0.05 \mathrm{M} \mathrm{H}_{2} \mathrm{SO}_{4}\right)$ at the corresponding wavelength. The fluorescence ratio (FR) was calculated as the ratio between the two RF values: $\mathrm{FR}=\mathrm{RF}_{393 / 463 \mathrm{~nm}} / \mathrm{RF}_{327 / 415 \mathrm{~nm}}$.

\subsection{Fatty acid analysis}

Acid-catalyzed transmethylation and methylation of total lipid extracts was carried out by employing acetyl chloride in dry methanol (Aubourg et al., 1996). At the same time, a base-catalyzed transmethylation method by employing sodium methoxide in anhydrous methanol was applied to the total lipid extracts so that the fatty acid composition of the total esterified lipid classes was obtained (Christie, 2003).

In both cases, resulting fatty acid methyl esters (FAME) were analyzed by means of a PerkinElmer 8700 chromatograph employing a fused silica capillary column SP-2330 (0.25 mm i.d. x 30 m, Supelco Inc., Bellefonte, PA, USA) (Aubourg et al., 1996). Nitrogen at 10 psi as carrier gas and 
flame ionization detector (FID) at $250^{\circ} \mathrm{C}$ were used. Peaks corresponding to fatty acids were identified by comparison of their retention times with standard mixtures (Larodan, Qualmix Fish, Malmo, Sweden; Supelco, FAME Mix, Bellefonte, PA, USA). Peak areas were automatically integrated, 19:0 fatty acid being used as internal standard for the quantitative analysis. The concentration of each fatty acid was calculated as $\mathrm{g} / 100 \mathrm{~g}$ total FAME.

\subsection{Non-lipid damage analyses}

Nucleotide degradation analysis was carried out starting from $6 \%$ perchloric acid extracts from the fish muscle according to previous research (Aubourg et al., 2005). Analysis was performed on HPLC, using a Beckman device provided with the programmable solvent module 126, and the scanning detector module 167 connected to the System Gold software, version 8.1 (Beckman Coulter, London, UK). Separations were achieved on a reverse-phase Spherisorb ODS2 C18 $250 \times 4.60 \mathrm{~mm}$ column (Waters, Milford, MA, USA), with an internal particle diameter of $5 \mu \mathrm{m}$. Standard curves for adenosine 5'-triphosphate (ATP) and each compound involved in its degradation pathway, adenosine 5'-diphosphate (ADP), adenosine 5'-monophosphate (AMP), inosine 5'-monophosphate (IMP), inosine (INO) and hypoxanthine $(\mathrm{Hx})$, were constructed in the 0-1 mM range. Results obtained for each degradation compound were calculated as mmol/ $\mathrm{kg}$ muscle. The $\mathrm{K}$ value was calculated according to the following concentration ratio:

$\mathrm{K}$ value $(\%)=100 \times(\mathrm{INO}+\mathrm{Hx}) /(\mathrm{ATP}+\mathrm{ADP}+$ +AMP+IMP+INO+Hx).

Trimethylamine (TMA) formation was determined by means of the picrate method, this including a spectrophotometric $(410 \mathrm{~nm})$ assessment (Beckman Coulter DU 640) (Tozawa et al., 1971). This involves the preparation of a $5 \%(\mathrm{w} / \mathrm{v})$ trichloroacetic acid extract of fish muscle. The results were expressed as mg TMA-N/ $100 \mathrm{~g}$ muscle.

\subsection{Statistical analyses}

Data $(n=3)$ obtained from the different chemical analyses were subjected to the ANOVA method to explore differences in two different ways: icing condition (FI/SI/OSI comparison) and icing time (Statsoft Inc., Statistica, version 6.0, 2001). A comparison of means was performed using the least-square differences (LSD) test. A confidence interval at the $95 \%$ level $(p<0.05)$ was considered in all cases.

\section{RESULTS AND DISCUSSION}

\subsection{Proximate analysis}

The lipid content of the turbot white muscle employed was included in the range of $0.77-1.10$ $\mathrm{g} / 100 \mathrm{~g}$ muscle, while moisture values ranged from 76.2 and $77.5 \mathrm{~g} / 100 \mathrm{~g}$ muscle. Values for these constituents did not provide significant differences $(p>0.05)$ as a result of the icing conditions, nor as a result of the icing time. The lipid content was found to be similar to the one reported for the same species obtained from cultured conditions (Sérot et al, 1998; Aubourg et al, 2005; Aubourg et al, 2007), but higher when compared to previous research on wild fish individuals (Sérot et al., 1998; Ruff et al., 2002). The moisture content agreed with previous data on farmed turbot (Sheehan et al., 1994; Aubourg et al., 2007), being lower than that obtained in previous research on wild fish (Sheehan et al., 1994; Ruff et al., 2002), according to a known inverse ratio between moisture and lipid matter (Piclet, 1987),

An increasing $\mathrm{NaCl}$ content in fish muscle was observed with icing time in individuals that were treated under any of the slurry ice conditions (SI and OSI systems; Table 1). This $\mathrm{NaCl}$ increase can be explained as a result of the $\mathrm{NaCl}$ presence in both slurry ice-systems employed, and agrees with previous research concerning wild species stored under SI conditions (Losada et al., 2004; Losada et al., 2005). As a result, a lower $\mathrm{NaCl}$ content was observed in fish muscle iced under FI condition for 3 and 6 days. Meantime, no effect of the ozone presence could be outlined on the $\mathrm{NaCl}$ content in turbot muscle.

In spite of this salt content increase with icing time, levels attained by SI- and OSI-treated fish can be considered as normal for a fish species (Piclet, 1987) and resulted in considerably lower levels than those determined in fish preserved in chilled seawater (Smith et al., 1980) or salted (Srikar et al., 1993).

\subsection{Lipid hydrolysis assessment}

The FFA content in the fish corresponding to day 1 showed values below $0.7 \%$ (Table 1$)$. This can be considered a low value when compared to other farmed lean fish species (Ortiz et al., 2008; Aubourg et al., 2010), taking into account that an inverse relationship between FFA and total lipid content is valuable in fish material (Piclet, 1987). Such low FFA values can mostly be explained by the fact that the fish employed was slaughtered in the current research, so that lipid hydrolysis as a result of previous post-mortem handling would not be likely to occur.

A low lipid hydrolytic activity is observed to occur after the slaughtering and chilled storage of the present farmed species under all treatments (Table 1). Mean values obtained for FFA formation showed a progressive increase in all cases as a result of increasing the icing time; however, this increase was only found significant in the case of the fish corresponding to both slurry ice systems (SI and $\mathrm{OSI}$ ). Comparison among fish corresponding to the different icing conditions showed higher mean values in the case of the OSI system. However, because of marked fish-to-fish differences, no 
Table 1

Assessment* of $\mathrm{NaCl}$ content and free fatty acid formation in turbot muscle after slaughtering and chilled storage in flake ice (FI), slurry ice (SI) or ozonized slurry ice (OSI), respectively**

\begin{tabular}{|c|c|c|c|c|}
\hline \multirow{2}{*}{ Parameter } & \multirow{2}{*}{ Icing Time } & \multicolumn{3}{|c|}{ Icing System } \\
\hline & & $\mathbf{F I}$ & SI & OSI \\
\hline \multirow{3}{*}{$\begin{array}{c}\text { NaCl content } \\
\text { (g/ 100g muscle) }\end{array}$} & 1 & $\begin{array}{c}0.07 \\
(0.02)\end{array}$ & $\begin{array}{l}0.09 \mathrm{a} \\
(0.02)\end{array}$ & $\begin{array}{l}0.08 \mathrm{a} \\
(0.01)\end{array}$ \\
\hline & 3 & $\begin{array}{l}\text { z } 0.09 \\
(0.01)\end{array}$ & $\begin{array}{c}\text { y } 0.13 \mathrm{~b} \\
(0.01)\end{array}$ & $\begin{array}{c}\text { y } 0.16 \text { b } \\
(0.04)\end{array}$ \\
\hline & 6 & $\begin{array}{l}z 0.11 \\
(0.02)\end{array}$ & $\begin{array}{c}\text { y } 0.20 \mathrm{c} \\
(0.01)\end{array}$ & $\begin{array}{c}\text { y } 0.18 \text { b } \\
(0.01)\end{array}$ \\
\hline \multirow{3}{*}{$\begin{array}{l}\text { Free Fatty Acid } \\
\text { formation } \\
\text { (g/ 100g lipids) }\end{array}$} & 1 & $\begin{array}{c}0.49 \\
(0.13)\end{array}$ & $\begin{array}{l}0.43 \mathrm{a} \\
(0.14)\end{array}$ & $\begin{array}{l}0.68 \mathrm{a} \\
(0.05)\end{array}$ \\
\hline & 3 & $\begin{array}{c}0.58 \\
(0.05)\end{array}$ & $\begin{array}{c}0.74 \mathrm{ab} \\
(0.26)\end{array}$ & $\begin{array}{c}0.85 \mathrm{ab} \\
(0.30)\end{array}$ \\
\hline & 6 & $\begin{array}{c}0.70 \\
(0.27)\end{array}$ & $\begin{array}{l}0.99 \mathrm{~b} \\
(0.27)\end{array}$ & $\begin{array}{l}1.21 \mathrm{~b} \\
(0.21)\end{array}$ \\
\hline
\end{tabular}

${ }^{*}$ Average values of three $(n=3)$ independent determinations. Standard deviations are indicated in parenthesis. ${ }^{* *}$ For each parameter and for each icing time, mean values preceded by different letters $(z, y)$ indicate significant differences $(p<0.05)$ as a result of icing system. For each parameter and for each icing condition, mean values followed by different letters $(a, b, c)$ denote significant ( $p<0.05)$ differences as a result of icing time.

significant differences could be concluded as a result of the icing condition.

FFA formation has been reported to be produced during the first stages of the chilling process (up to days 7-10, approximately) as a result of endogenous enzyme (namely, lipases and phospholipases) activity (Whittle et al., 1990; Olafsdóttir et al., 1997). Later on, microbial activity should gain importance, so that FFA formation is then mostly produced as a result of bacterial catabolic processes. According to this profile, present results on FFA formation in turbot muscle should correspond to endogenous enzyme activity, this increasing with the icing time up to day 6. Previous research has shown that $\mathrm{NaCl}$ presence in fish muscle can lead to a decrease in endogenous proteolysis development, so that lipases and phospholipases would be retained in a higher proportion and accordingly, be able to provide a higher lipid hydrolysis development (Huidobro et al., 1990). This behavior could explain the higher mean values found for the fish treated under OSI conditions when compared to the FItreated fish. On the other hand, an opposite effect of $\mathrm{NaCl}$ presence on FFA formation has been depicted for advanced chilling stages. Thus, when the lag phase is ended and microbial activity should be important, a marked inhibitory effect of $\mathrm{NaCl}$ (Chaouqy et al., 2008) or other kinds of salt (Hwang and Regenstein, 1995) presence on lipid hydrolysis formation has been recognised as a result of microbial activity inhibition.

\subsection{Lipid oxidation assessment}

Lipid oxidation was studied by means of different quality indexes corresponding to different steps included in the fish lipid oxidation mechanism development.

Peroxide formation (primary oxidation) showed a progressive increase with time in all cases (Table 2). At day 1, low values were obtained, according to a starting fish material that was directly slaughtered under known conditions. Values found at the end of the experiment can be considered relatively low $(<5.0)$, so that primary oxidation development cannot be considered important for the icing period considered in the present study. Comparison among treatments showed a pro-oxidant effect of ozone presence; thus, higher mean values were obtained for the fish treated under OSI condition, being significantly higher at day 6 .

Assessment of thiobarbituric acid reactive substances (TBARS; secondary lipid oxidation) also showed a progressive increase with icing time in all kinds of samples (Table 2). However, this increase was important in fish corresponding to the OSI condition; thus, higher TBA values were obtained at days 3 and 6 for the fish material treated under such icing system. Accordingly, a pro-oxidant effect of ozone presence could be concluded, although scores obtained were in all cases below 1.0 and cannot be considered high. At the same time, no differences were obtained between fish individuals corresponding to SI and FI systems.

Interaction compound formation between oxidized lipids and nucleophilic compounds (namely, proteinlike molecules; tertiary lipid oxidation) was assessed according to the fluorescence ratio (Table 2). This analysis provided relatively low values in all cases throughout the whole study, so that no differences could be concluded as a result of the icing condition and the icing time employed. It is considered that tertiary oxidation compound formation would be 
Table 2

Assessment of lipid oxidation development* in turbot muscle after slaughtering and chilled storage in flake ice (FI), slurry ice (SI) or ozonized slurry ice (OSI), respectively**

\begin{tabular}{|c|c|c|c|c|}
\hline \multirow{2}{*}{ Parameter } & \multirow{2}{*}{ Icing Time } & \multicolumn{3}{|c|}{ Icing System } \\
\hline & & FI & SI & OSI \\
\hline \multirow{4}{*}{$\begin{array}{c}\text { Peroxide value } \\
\text { (meq active oxygen/ kg lipids) }\end{array}$} & 1 & $\begin{array}{l}0.85 a \\
(0.02)\end{array}$ & $\begin{array}{l}0.79 \mathrm{a} \\
(0.10)\end{array}$ & $\begin{array}{l}0.91 a \\
(0.14)\end{array}$ \\
\hline & 3 & $\begin{array}{l}1.55 b \\
(0.51)\end{array}$ & $\begin{array}{l}1.73 \mathrm{~b} \\
(0.70)\end{array}$ & $\begin{array}{l}2.31 \mathrm{~b} \\
(0.38)\end{array}$ \\
\hline & 6 & $\begin{array}{c}z 2.81 b \\
(0.92)\end{array}$ & $\begin{array}{c}\text { z } 3.26 \text { c } \\
(0.51)\end{array}$ & $\begin{array}{c}\text { y } 4.81 \text { c } \\
(0.64)\end{array}$ \\
\hline & 1 & $\begin{array}{c}0.09 \\
(0.04)\end{array}$ & $\begin{array}{c}0.17 \\
(0.10)\end{array}$ & $\begin{array}{l}0.19 a \\
(0.07)\end{array}$ \\
\hline \multirow{3}{*}{$\begin{array}{c}\text { Thiobarbituric acid index } \\
\text { (mg malondialdehyde/ kg muscle) }\end{array}$} & 3 & $\begin{array}{l}z 0.08 \\
(0.06)\end{array}$ & $\begin{array}{c}\text { zy } 0.21 \\
(0.08)\end{array}$ & $\begin{array}{c}\text { y } 0.31 \text { a } \\
(0.08)\end{array}$ \\
\hline & 6 & $\begin{array}{l}z 0.12 \\
(0.06)\end{array}$ & $\begin{array}{l}z 0.26 \\
(0.11)\end{array}$ & $\begin{array}{l}\text { y } 0.81 \text { b } \\
(0.29)\end{array}$ \\
\hline & 1 & $\begin{array}{c}0.35 \\
(0.10)\end{array}$ & $\begin{array}{c}0.33 \\
(0.08)\end{array}$ & $\begin{array}{c}0.40 \\
(0.08)\end{array}$ \\
\hline \multirow[t]{2}{*}{ Fluorescence ratio } & 3 & $\begin{array}{c}0.33 \\
(0.09)\end{array}$ & $\begin{array}{c}0.37 \\
(0.07)\end{array}$ & $\begin{array}{c}0.42 \\
(0.03)\end{array}$ \\
\hline & 6 & $\begin{array}{c}0.39 \\
(0.06)\end{array}$ & $\begin{array}{c}0.36 \\
(0.07)\end{array}$ & $\begin{array}{c}0.48 \\
(0.06)\end{array}$ \\
\hline
\end{tabular}

${ }^{*}$ Average values of three $(n=3)$ independent determinations. Standard deviations are indicated in parenthesis. ${ }^{* *}$ For each quality index and for each icing time, mean values preceded by different letters $(z, y)$ indicate significant differences $(p<0.05)$ as a result of icing system. For each quality index and for each icing condition, mean values followed by different letters (a, b, c) denote significant differences $(p<0.05)$ as a result of icing time.

likely to be negligible due to the fact that primary and secondary oxidation development was low under the present slaughtering and chilling conditions (Aubourg, 1999).

As in the present experiment, a low lipid oxidation development was already found in chilled farmed turbot under $\mathrm{FI}$ conditions after a similar (5-9 days) storage period (Aubourg et al., 2005). When wild turbot was studied (Ruff et al., 2002; Özogul et al., 2006), higher peroxide and TBA values were obtained, these being explained as a result of a post-mortem storage period previous to the start of the experiment. According to the primary and secondary lipid oxidation indexes (Table 2), fish treated under the OSI system has shown a higher lipid oxidation level in the present study. According to this result, a pro-oxidant effect of ozone has already been observed when studying the chilling storage of other related farmed species. Thus, higher lipid oxidation levels were obtained for rainbow trout (Ortiz et al., 2008) and blackspot seabream (Álvarez et al., 2009) slaughtered and chilled under OSI conditions when compared to their counterparts under the SI system. Finally, the same pro-oxidant effect (TBA-i assessment) was observed in the case of a wild species (sardine; Losada et al., 2004).

A further explanation for the higher lipid oxidation found in OSI-treated fish might be the salt presence increase in fish muscle. In this sense, previous research carried out on fatty fish species such as mackerel (Maruf et al., 1990) and anchovy (Chaouqy et al., 2008) has shown the important effect of $\mathrm{NaCl}$ presence on lipid oxidation development. Sodium chloride has been reported to act as a pro-oxidant by enhancement of the pro-oxidant effect of chelatable iron ions (Kanner et al., 1991) widely present in fish muscle, especially in the dark one (Ackman, 1989).

\subsection{Fatty acid composition}

Fish species have attracted a great amount of attention from consumers as a source of important nutritional polyunsaturated fatty acid (PUFA) (namely, docosahexaenoic and eicosapentaenoic acids) components for the human diet (Ackman, 1989). In the present study, the fatty acid composition of turbot muscle was studied in the total lipid extract of the different kinds of samples. In all cases, the most abundant fatty acid was $\mathrm{C}$ 22:6w3 (docosahexaenoic acid, DHA), followed by C 16:0 (palmitic acid), C 20:5 03 (eicosapentaenoic

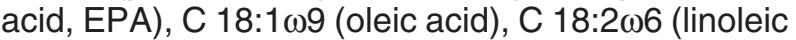
acid) and C 22:5 13 (docosapentaenoic acid, DPA).

The damage suffered by the PUFA included in the total lipid extract was measured by PI analysis. Thus, a PI ranging from 2.33 and 2.58 was found in all kinds of samples (Table 3 ). This value range can be considered similar to that recently reported for the same farmed species (Aubourg et al., 2007), but 
Table 3

Assessment of polyene index * in the total lipid extract and in the esterified lipid fraction from turbot muscle after slaughtering and chilled storage in flake ice (FI), slurry ice (SI) or ozonized slurry ice (OSI), respectively**

\begin{tabular}{|c|c|c|c|c|}
\hline \multirow{2}{*}{ Parameter } & \multirow{2}{*}{ Icing Time } & \multicolumn{3}{|c|}{ Icing System } \\
\hline & & FI & SI & OSI \\
\hline \multirow{3}{*}{$\begin{array}{c}\text { Polyene Index } \\
\text { (total lipid fraction) }\end{array}$} & 1 & $\begin{array}{c}2.49 \\
(0.11)\end{array}$ & $\begin{array}{c}2.33 \\
(0.08)\end{array}$ & $\begin{array}{c}2.46 \\
(0.11)\end{array}$ \\
\hline & 3 & $\begin{array}{c}2.52 \\
(0.08)\end{array}$ & $\begin{array}{l}2.51 \\
(0.06)\end{array}$ & $\begin{array}{c}2.45 \\
(0.08)\end{array}$ \\
\hline & 6 & $\begin{array}{c}2.52 \\
(0.17)\end{array}$ & $\begin{array}{c}2.58 \\
(0.05)\end{array}$ & $\begin{array}{c}2.50 \\
(0.17)\end{array}$ \\
\hline \multirow{3}{*}{$\begin{array}{c}\text { Polyene Index } \\
\text { (esetrified lipid fraction) }\end{array}$} & 1 & $\begin{array}{c}2.61 \\
(0.13)\end{array}$ & $\begin{array}{c}2.53 \\
(0.09)\end{array}$ & $\begin{array}{c}2.62 \\
(0.12)\end{array}$ \\
\hline & 3 & $\begin{array}{c}2.53 \\
(0.12)\end{array}$ & $\begin{array}{c}2.62 \\
(0.13)\end{array}$ & $\begin{array}{l}2.55 \\
(0.11)\end{array}$ \\
\hline & 6 & $\begin{array}{c}2.51 \\
(0.15)\end{array}$ & $\begin{array}{c}2.64 \\
(0.15)\end{array}$ & $\begin{array}{c}2.62 \\
(0.09)\end{array}$ \\
\hline
\end{tabular}

* Average values of three $(n=3)$ independent determinations. Standard deviations are indicated in parenthesis.

** For both lipid fractions, no significant differences $(p>0.05)$ as a result icing system and icing time were obtained.

higher than that obtained in older studies (Sheehan et al., 1994; Sérot et al., 1998). Differences can be explained as a result of a great dependence of fatty acid composition on the fatty acid composition of the fish food (Yildiz et al, 2008). Additionally, present results provided a lower $\mathrm{PI}$ range than that obtained for the same fish species from wild sources (Aubourg et al., 2007), according to a known wild/farmed pattern distribution (Sheehan et al., 1994; Sérot et al., 1998).

In the present research, the PI of total lipid extract did not provide differences among treatments at any of the icing times. In addition, no differences could be assessed as a result of the icing time for any of the icing conditions tested. Increases found for lipid damage indexes can be considered low and accordingly, have not produced a decreasing effect on PUFA content. These results agree with previous conclusions for rainbow trout, where no PI differences were found between fish individuals treated under SI and OSI conditions, respectively (Ortiz et al., 2008). On the contrary, previous research (Aubourg et al., 1998) has shown an important negative effect of lipid oxidation development on the PUFA content (PI decrease) during the chilled storage of a wild lean species (blue whiting; Micromesistius poutassou).

A complementary analysis was carried out on fatty acid composition. In order not to take into account the FFA fraction (endogenous composition and hydrolysis formation during slaughtering and chilling storage), fatty acid composition was studied in the total esterified lipid classes. A similar fatty acid composition was observed, with the most abundant ones being those above reported for the total lipid analysis. This lack in difference agrees with the fact that low FFA formation and contents were observed (Table 1). For the esterified classes, PI scores ranged from 2.51 and 2.64 (Table 3), and were not found significantly different from those obtained for total lipid extracts. However, the fact that higher mean $\mathrm{PI}$ values were obtained in total esterified lipid classes agrees with previous research that proves that PUFA are mostly retained in the esterified form in the living metabolism and are preferentially preserved from hydrolysis during storage (Pearson et al., 1977; Schewfelt, 1981; Aubourg et al., 2006).

\subsection{Non-lipid damage assessment}

The $\mathrm{K}$ value (\%) was calculated according to the concentration of the six molecules included in the nucleotide degradation pathway. Its assessment (Figure 1) showed very low values at day 1 , according to a high quality starting raw fish. Then, progressive and marked increases $(p<0.05)$ could be depicted in all cases with icing time. This increase was shown to be higher $(p<0.05)$ in the case of fish corresponding to the FI treatment. It is concluded that both conditions including slurry ice have led to a lower nucleotide degradation, an effect that is produced as a result of the lower icing temperature encountered (Medina et al., 2009). This preservative effect was previously observed in farmed turbot (Rodriguez et al., 2006) and in wild species (Losada et al., 2004; Losada et al., 2005) when the SI condition was employed as a chilled storage procedure in replacement of the FI treatment. Additionally, no effect of the ozone presence could be concluded on the $\mathrm{K}$ value in the present study, according to previous research on farmed blackspot seabream (Álvarez et al., 2009) and in wild sardine (Losada et al., 2004).

Microbial activity was analyzed in the present study by assessment of the TMA formation (Figure 2). According to a short icing time period, low 


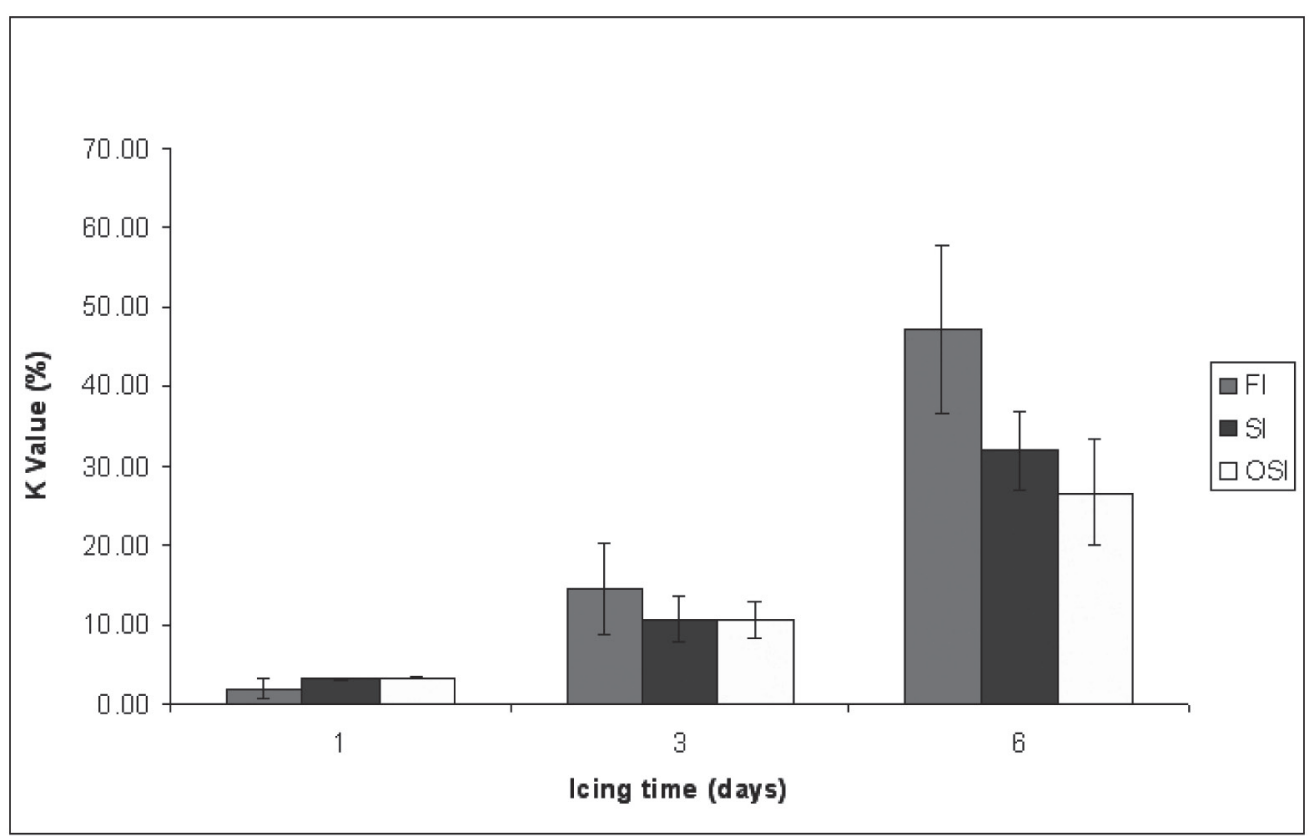

Figure 1

$\mathrm{K}$ value (\%) assessment in turbot muscle after slaughtering and chilled storage in flake ice (FI), slurry ice $(\mathrm{SI})$ or ozonized slurry ice $(\mathrm{OSI})$, respectively. Average values of three $(n=3)$ independent determinations. Standard deviations are indicated by bars.

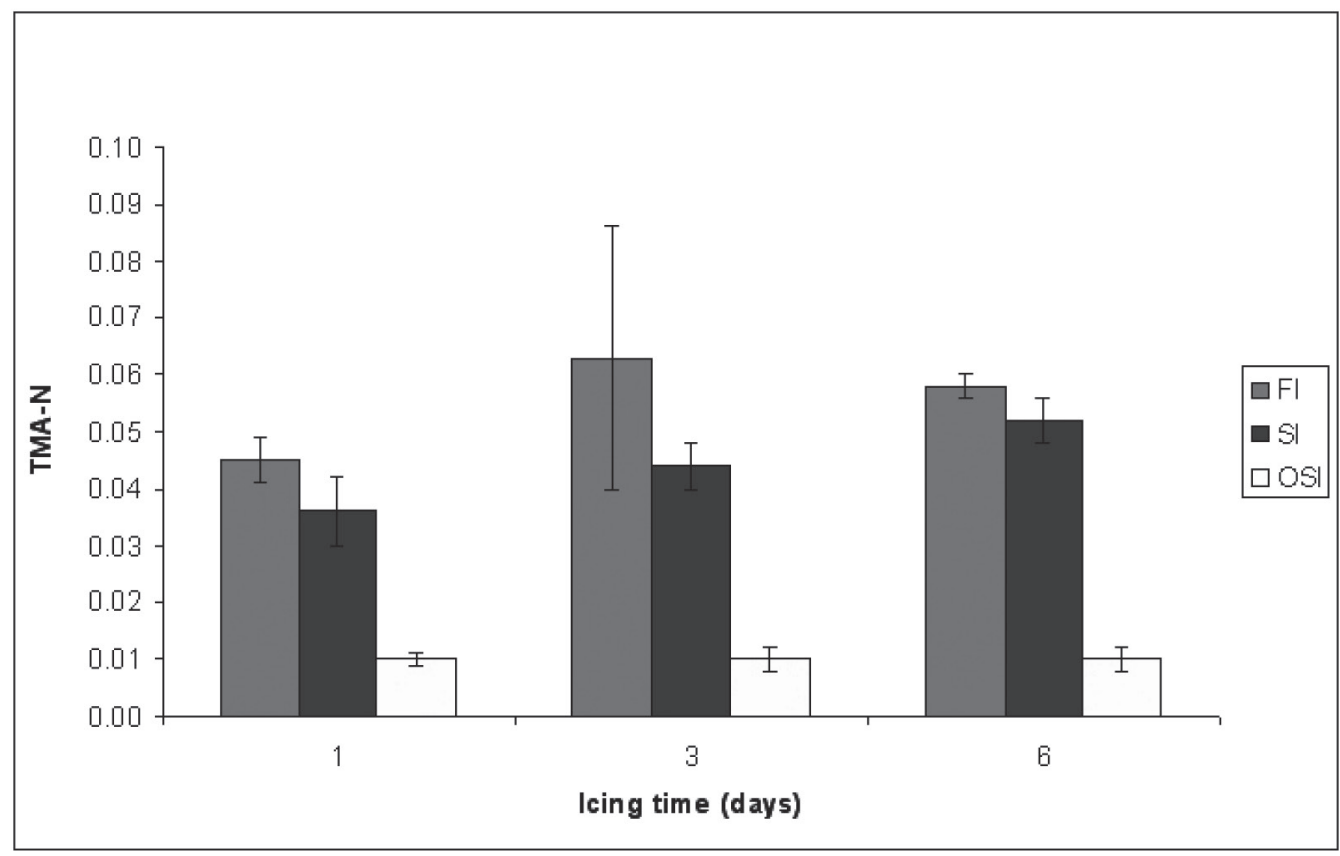

Figure 2

Trimethylamine-N (TMA-N) content in turbot muscle after slaughtering and chilled storage in flake ice (FI), slurry ice (SI) or ozonized slurry ice (OSI), respectively. Average values (mg TMA-N/ 100g muscle) of three $(n=3)$ independent determinations. Standard deviations are indicated by bars

values for TMA formation $(<0.07 \mathrm{mg}$ TMA-N/ 100g muscle) were obtained in agreement with previous research on other related farmed species such as blackspot seabream (Álvarez et al., 2009), rainbow trout (Ortiz et al., 2008) and gilthead seabream (Aubourg et al., 2010), where the slaughtering step followed by chilled storage was encountered as in the present study. According to previous studies, the lag phase of microorganisms has not been likely to be reached under the present experimental conditions, so that microbial activity development has been found low (Whittle et al., 1990). On the contrary, higher raw TMA values were obtained by Özogul et al. (2006) for wild turbot and such high values may be explained as a result of post-mortem spoilage before the chilling study starts. 
An important inhibitory effect $(p<0.05)$ of ozone presence on TMA formation could be concluded throughout the whole experiment (Figure 2). This conclusion agrees with previous research where an antiseptic effect of ozone was concluded when also employed during both slaughtering and chilling stages (rainbow trout, Ortiz et al, 2008). At the same time (Figure 2), lower mean values were obtained for fish from the SI condition when compared to fish from the FI treatment, so that an inhibitory effect could also be proven as a result of SI employment, according to previous research showing the advantages of SI employment in replacement of the FI condition (Rodríguez et al., 2006; Aubourg et al., 2010)

\section{CONCLUSIONS}

Previous research has shown that stress at the time of slaughtering has a large influence on meat quality, so that an optimal slaughtering technique may substantially increase the quality of the flesh. According to the present results on lipid damage development, nucleotide degradation and TMA formation, a low quality loss could be assessed in all kinds of turbot muscle as a result of slaughtering and chilled storage up to six days. It has been proved that all ice-slaughtering procedures tested in the present experiment were found benefitial in order to inhibit quality losses when the same icing condition was further employed during the postmortem chilled storage.

The presence of ozone has led to some negative effects on the primary and secondary lipid oxidation development, with no effect on tertiary lipid oxidation compounds or lipid hydrolysis formation. However, oxidation values reached by individuals kept under OFI conditions can not be considered high, so that in fact, no differences were assessed in the PUFA content. In contrast, ozone has shown its reported preservative role as a microbial inhibitor by slowing down the TMA formation, probably contributing to extending the shelf life of this chilled fish product.

The employment of $\mathrm{SI}$ as a slaughtering and chilling strategy was found useful in order to partially inhibit quality losses in chilled turbot. Thus, a lower $\mathrm{K}$ value degradation and TMA formation could be observed when compared to their counterpart fish treated under the FI condition. In addition, SI-treated fish did not provide an enhancement in lipid oxidation development, in spite of the fact that a slight $\mathrm{NaCl}$ content increase is found in its corresponding fish muscle.

\section{ACKNOWLEDGEMENTS}

This work was supported through a project grant by the Secretaría Xeral de I+D from the Xunta de Galicia (Project PGIDIT 05 TAL 00701 CT). The authors thank Mr. Marcos Trigo for his excellent technical assistance, Isidro de la Cal (La Coruña,
Spain) for providing the farmed turbot, Kinarca S.A.U. (Vigo, Spain) for providing the slurry ice equipment and Cosemar Ozono (Madrid, Spain) for providing the ozonized prototype.

\section{REFERENCES}

Ackman R. 1989. Fatty acids in Ackman R (Ed.) Marine Biogenic Lipids, Fats and Oils, Vol. 1, pp. 103-137. CRC Press, Boca Raton, FI, USA.

Álvarez V, Feás X, Barros-Velázquez J, Aubourg S. 2009. Quality changes of farmed blackspot seabream (Pagellus bogaraveo) subjected to slaughtering and storage under flow ice and ozonised flow ice. Int. J. Food Sci. Technol. 44, 1561-1571.

AOAC. 1990. Official methods of analysis of the Association of Analytical Chemistry, $15^{\text {th }}$ ed., vol. 2, p. 870. Association of Official Analytical Chemists, Washington, DC, USA.

Aubourg S, Álvarez V, Pena J. 2010. Lipid hydrolysis and oxidation in farmed gilthead seabream (Sparus aurata) slaughtered and chilled under different icing condition. Grasas y Aceites 61, 183-190.

Aubourg S, Losada V, Prego R. 2007. Distribution of lipids and trace minerals in different muscle sites of farmed and wild turbot (Psetta maxima). Int. J. Food Sci. Technol. 42, 1456-1464.

Aubourg S, Medina I, Gallardo J. 1998. Quality assessment of blue whiting (Micromesistius poutassou) during chilled storage by monitoring lipid damages. J. Agric. Food Chem. 46, 3662-3666.

Aubourg S, Medina I, Pérez-Martín R. 1996. Polyunsaturated fatty acids in tuna phospholipids: distribution in the sn2 location and changes during cooking. J. Agric. Food Chem. 44, 585-589.

Aubourg S, Piñeiro C, Gallardo J, Barros-Velázquez J. 2005. Biochemical changes and quality loss during chilled storage of farmed turbot (Psetta maxima). Food Chem. 90, 445-452.

Aubourg S. 1999. Recent advances in assessment of marine lipid oxidation by using fluorescence. J. Amer. Oil Chem. Soc. 76, 409-419.

Bligh E, Dyer W. 1959. A rapid method of total extraction and purification. Can. J. Biochem. Physiol. 37, 911917.

Chaouqy NE, Gallardo JM, El Marrakchi A, Aubourg S. 2008. Lipid damage development in anchovy (Engraulis encrasicholus) muscle during storage under refrigerated conditions. Grasas y Aceites 59, 309-315.

Chapman R, McKay J. 1949. The estimation of peroxides in fats and oils by the ferric thiocyanate method. $J$. Amer. Oil Chem. Soc. 26, 360-363.

Christie W. 2003. Lipid Analysis, $3^{\text {rd }}$ edition, p. 37. The Oily Press, Bridgwater, UK.

Duran A, Erdemli U, Karakaya M, Yilmaz M. 2008. Effects of slaughter methods on physical, biochemical and microbiological quality of rainbow trout Oncorhynchus mykiss and mirror carp Cyprinus carpio filleted in pre-, in- or post-rigor periods. Fish. Sci. 74, 1146-1156.

FAO. 2007. Fishery statistics. Aquaculture production. In Food and Agriculture Organization of the United Nations, Yearbook 2005, Vol. 100/2, p. 78, Rome, Italy.

Gregory N. 2005. Review: Recent concerns about stunning and slaughter. Meat Sci. 70, 481-491.

Huidobro A, Mendes R, Nunes ML. 2001. Slaughtering of gilthead seabream (Sparus aurata) in liquid ice: influence on fish quality. Eur. Food Res. Technol. 213, 267-272. 
Huidobro A, Montero $P$, Tejada $M$, Jiménez-Colmenero F, Borderías J. 1990. Changes in protein function of sardines stored in ice with and without added salt. $Z$. Lebensm Unters Forsch. 190, 195-198.

Hwang K, Regenstein J. 1995. Hydrolysis and oxidation of mackerel (Scomber scombrus) mince lipids with $\mathrm{NaOCl}$ and $\mathrm{NaF}$ treatments. J. Aquat. Food Prod. Technol. 4, 19-30.

Kanner J, Harel S, Jaffe R. 1991. Lipid peroxidation of muscle food as affected by sodium chloride. J. Agric. Food Chem. 39, 1017-1021.

Kim J, Yousef A, Dave S. 1999. Application of ozone for enhancing the microbiological safety and quality of foods: A review. J. Food Prot. 62, 1071-1087.

Losada V, Barros-Velázquez J, Gallardo J, Aubourg, S. 2004. Effect of advanced chilling methods on lipid damage during sardine (Sardina pilchardus) storage. Eur. J. Lipid Sci. Technol. 106, 844-850.

Losada V, Piñeiro C, Barros-Velázquez J, Aubourg S. 2005. Inhibition of chemical changes related to freshness loss during storage of horse mackerel (Trachurus trachurus) in slurry ice. Food Chem. 93, 619-625.

Lowry R, Tinsley I. 1976. Rapid colorimetric determination of free fatty acids. J. Amer. Oil Chem. Soc. 53, 470472.

Maruf F, Ledward D, Neale R, Poultier R. 1990. Chemical and nutritional quality of Indonesian dried-salted mackerel (Rastrelliger kanagurta). Int. J. Food Sci. Technol. 25, 66-77.

Medina I, Gallardo JM, Aubourg S. 2009. Quality preservation in chilled and frozen fish products by employment of slurry ice and natural antioxidants. Int. J. Food Sci. Technol. 44, 1467-1479.

Morzel M, Sohier D, Van de Vis H. 2003. Evaluation of slaughtering methods for turbot with respect to animals welfare and flesh quality. J. Sci. Food Agric. 83, 19-28.

Olafsdóttir G, Martinsdóttir E, Oehlenschläger J, Dalgaard $P$, Jensen B, Undeland I, Mackie I, Henehan G, Nielsen J, Nilsen H. 1997. Methods to evaluate fish freshness in research and industry. Trends Food Sci. Technol. 8, 258-265.

Ortiz J, Palma Ó, González N, Aubourg S. 2008. Lipid damage in farmed rainbow trout (Oncorhynchus mykiss) after slaughtering and chilled storage. Eur. J. Lipid Sci. Technol. 110, 1127-1135.

Özogul Y, Özogul F, Kuley E, Serhat Özkutuk A, Gökbulut C, Köse S. 2006. Biochemical, sensory and microbiological attributes of wild turbot (Scophthalmus maximus), from the Black Sea, during chilled storage. Food Chem. 99, 752-758.

Özogul Y, Özogul F. 2004. Effects of slaughtering methods on sensory, chemical and microbiological quality of rainbow trout (Oncorhynchus mykiss) stored in ice and MAP. Eur. Food Res. Technol. 219, 211-216.

Pearson A, Love J, Shorland B. 1977. Warmed over flavor in meat, poultry and fish. Adv. Food Res. 23, 2-61.

Piclet G. 1987. Le poisson aliment. Composition et intérêt nutritionnel. Cah. Nutr. Diét. 22, 317-335.
Rodríguez Ó, Barros-Velázquez J, Piñerio C, Gallardo J, Aubourg S. 2006. Effects of storage in slurry ice on the microbial, chemical and sensory quality and on the shelf life of farmed turbot (Psetta maxima). Food Chem. 95, 270-278.

Roth B, Imsland A, Gunnarsson S, Foss A, Schelvis-Smit R. 2007. Slaughter quality and rigor contraction in farmed turbot (Scophthalmus maximus); a comparison between different stunning methods. Aquaculture 272, 754-761.

Ruff N, Fitzgerald R, Cross T, Kerry J. 2002. Comparative composition and shelf-life of fillets of wild and cultured turbot (Scophthalmus maximus) and Atlantic halibut (Hippoglossus hippoglossus). Aquac. Int. 10, 241-256.

Sérot L, Gandemer G, Demaimay M. 1998. Lipid and fatty acid compositions of muscle from farmed and wild adult turbot. Aquac. Int. 6, 331-343.

Sheehan E, Sheehy P, Morrisey P, Fitzgerald R. 1994. Compositional analysis on wild and farmed turbot and fish feeds in Ireland in Lavens $P$, Remmerswaal R (Eds.) Turbot culture: Problems and prospects, pp. 302-311. European Aquaculture Society, Special Publication No. 22, Gent, Belgium.

Shewfelt R. 1981. Fish muscle lipolysis. A review. J. Food Biochem. 5, 79-100.

Smith J, Hardy R, McDonald I, Templeton J. 1980. The storage of herring (Clupea harengus) in ice, refrigerated sea water and at ambient temperature. Chemical and sensory assessment. J. Sci. Food Agric. 31, 375-385.

Srikar L, Khuntia B, Reddy G, Srinivasa B. 1993. Influence of storage temperature on the quality of salted mackerel (Rastrelliger kangurta) and pink perch (Nemipterus japonicus). J. Sci. Food Agric. 63, 319-322.

Tozawa H, Erokibara K, Amano K. 1971. Proposed modification of Dyer's method for trimethylamine determination in codfish in Kreuzer R. (Ed.) Fish Inspection and Quality Control, pp. 187-190. Fishing News Books Ltd., London, UK.

Vyncke W. 1970. Direct determination of the thiobarbituric acid value in trichloracetic acid extracts of fish as a measure of oxidative rancidity. Fette Seifen Anstrichm. 72, 1084-1087.

Whittle K, Hardy R, Hobbs G. 1990. Chilled fish and fishery products in Gormley T. (Ed.) Chilled foods: The state of the art, pp. 87-116. Elsevier Applied Science, New York, USA.

Yamada M, Fukusako S, Kawanami T. 2002. Performance analysis on the liquid-ice thermal storage system for optimum operation. Int. J. Refrig. 25, 267-277.

Yildiz M, Sener E, Timur M. 2008. Effect of differences in diet and seasonal changes on the fatty acid composition in fillets from farmed and wild sea bream (Sparus aurata L.) and sea bass (Dicentrarchus labrax). Int. J. Food Sci. Technol. 43, 853-858. 